\title{
Identification of active fossil bubbles based on coordinated VHF radar and airglow measurements
}

\author{
R. Sekar ${ }^{1}$, D. Chakrabarty ${ }^{1}$, S. Sarkhel ${ }^{1}$, A. K. Patra ${ }^{2}$, C. V. Devasia ${ }^{3}$, and M. C. Kelley ${ }^{4}$ \\ ${ }^{1}$ Physical Research Laboratory, Ahmedabad, India \\ ${ }^{2}$ National Atmospheric Research Laboratory, Gadanki, India \\ ${ }^{3}$ Space Physics Laboratory, Vikram Sarabhai Space Center, Thiruvananthapuram, India \\ ${ }^{4}$ School of Electrical and Computer Engineering, Cornell University, Ithaca, NY, USA
}

Received: 13 July 2007 - Accepted: 5 October 2007 - Published: 6 November 2007

\begin{abstract}
Plasma irregularity structures associated with an Equatorial Spread-F (ESF) event were recorded by the Indian VHF Radar on 26-27 April 2006 near midnight hours. The plasma structures were found to be isolated without having bottomside structure. They moved predominantly downward and the structures were found to be less turbulent than their post-sunset counterparts. However, the structures were characterized by meter-scale size irregularities. These structures are identified for the first time as plasma depletion structures using simultaneous, collocated measurements of OI $630.0 \mathrm{~nm}$ airglow intensity variations. The variation of the base height of ionospheric $\mathrm{F}$ layer over dip equator is also presented to buttress the result. Further, these plasma structures are shown to be "active fossil bubbles".
\end{abstract}

Keywords. Ionosphere (Equatorial ionosphere; Ionospheric irregularities; Plasma waves and instabilities)

\section{Introduction}

The depleted plasma region commonly known as plasma bubbles associated with equatorial spread $\mathrm{F}$ events have been observed (Kelley, 1985) by several techniques and simulated theoretically (Ossakow, 1981; Sekar et al., 1994) by nonlinear numerical models. Seed perturbations in the ambient electron density with appropriate background ionospheric conditions evolve nonlinearly under the action of generalized Rayleigh-Taylor instability mechanism to form plasma bubbles. The background ionospheric conditions such as the F-region peak height and steep plasma density gradients are, in general, suitable during post sunset time for the generation of such plasma bubbles. These plasma bubbles evolve nonlinearly and penetrate F-region peak altitude and thereby, account for the generation of irregularities in topside of the

Correspondence to: R. Sekar

(rsekar@prl.res.in) ionosphere. During that time period, meter-scale (m-scale) irregularities are found throughout the plasma depletion.

The background ionospheric conditions near midnight are not conducive, in general, except during some magnetically active times (Chakrabarty et al., 2006) for further development of plasma bubbles. In addition to that, westward electric field during nighttime decelerates the growth of the plasma bubbles. Sometimes, the remnants of such plasma bubbles drift zonally into the field of view of measuring instruments causing spread $\mathrm{F}$ like signatures. These kind of non-evolving remnant plasma bubbles are generally termed as "fossil bubbles". On most of the occasions, the m-scale structures detectable by VHF radars disappear during this non-evolving phase leaving larger scale structures in place (Basu et al., 1978). However, the reported fossil structures in this communication have m-scale irregularities.

These fossil bubbles normally drift towards east with ambient plasma motion. Though, the electron density is depleted inside such bubbles, they tend to move downward similar to the ambient plasma. In general, they detach from where they are originated and may appear as detached patches after post-midnight. Several indications of the presence fossil bubbles were obtained using earlier studies. In addition to Basu et al. (1978), Argo and Kelley (1986) using digital ionosonde with capability to identify echo location, tentatively identified a "fossil plume" which was observed as isolated scattering patches moving with ambient plasma. The implications of the "fossil bubble" in the development of post-midnight onset of ESF during June solstice of the solar minimum period where the ionosphere background condition was not conducive for plasma instability mechanism, were discussed in detail by Sastri (1999). Recently, Fukao et al. (2005) discussed the implication of moving structures from west of EAR VHF radar site using beam steering technique. None of these techniques were capable of identifying whether the structures were depleted plasma region or enhanced region which normally moves downward.

Published by Copernicus Publications on behalf of the European Geosciences Union. 

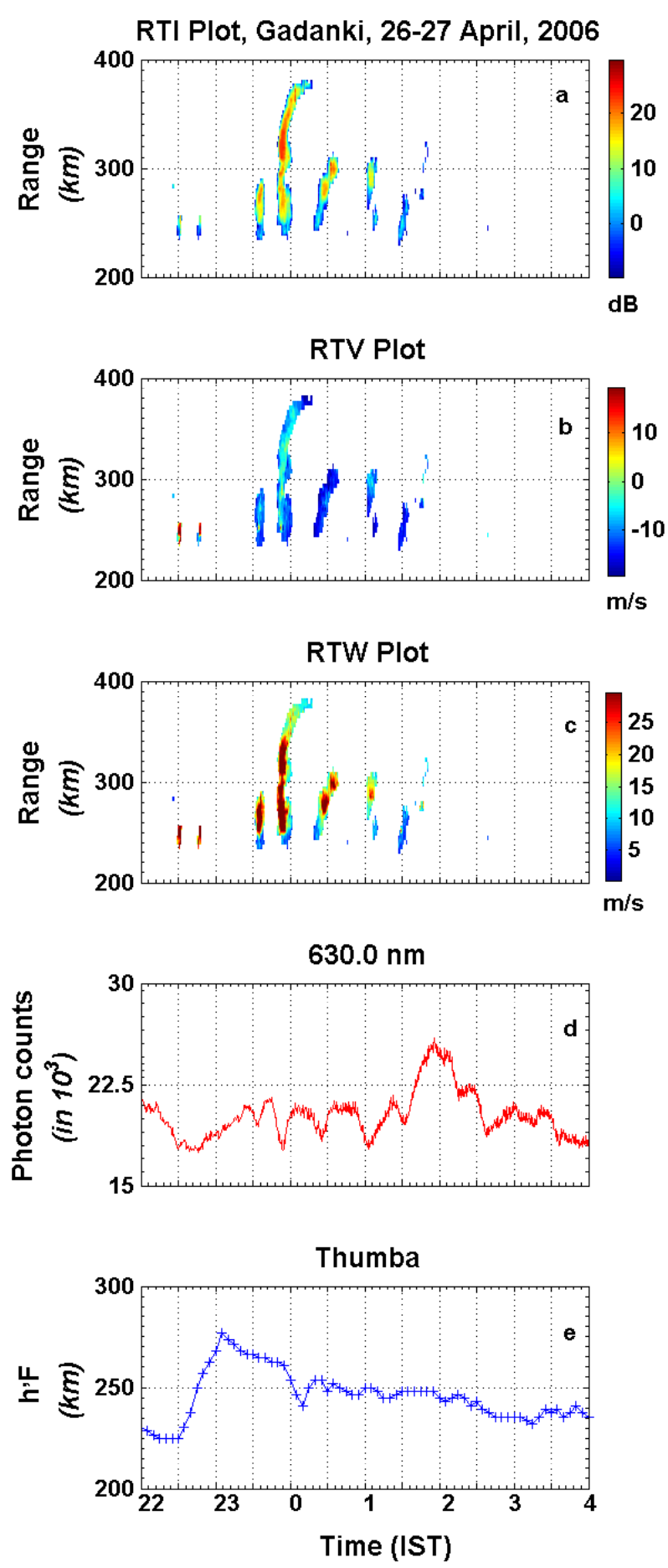

Fig. 1. Equatorial Spread F (ESF) structures on 26-27 April 2006 as revealed by (a) Range-Time-Intensity (RTI) plot, (b) Range-TimeVelocity (RTV) plot, (c) Range-Time-Width (RTW) along with corresponding temporal variations in OI $630.0 \mathrm{~nm}$ airglow (maximum measurement error $\sim \pm 160$ photon counts) measurements and the base of the $F$ layer (uncertainty $\sim \pm 5 \mathrm{~km}$ ) over dip equator are shown in (d) and (e).
It is essentially due to the fact that the return echo strength of a VHF radar is proportional to square of electron density fluctuations while it is well known that the bubbles cannot be detected by ground based ionosondes. In this communication, an example is provided for "fossil bubbles" which have m-scale irregularities. A possible physical scenario is also invoked wherein the "fossil bubbles" can still be "active" enough to allow generation of m-scale irregularities.

\section{Details of observations}

Coordinated observations from Gadanki $\left(13.5^{\circ} \mathrm{N}, 79.2^{\circ} \mathrm{E}\right.$, dip lat $6.3^{\circ} \mathrm{N}$ ) were carried out on a campaign mode during April 2006 using VHF radar in ionospheric mode and OI $630.0 \mathrm{~nm}$ airglow observations with a narrow band photometer. The VHF radar operates at $53 \mathrm{MHz}$ and can attain a maximum power aperture product of $3 \times 10^{10} \mathrm{~W} \mathrm{~m}^{2}$. The radar was operated in ionospheric mode wherein the beam was oriented $\left(14.8^{\circ} \mathrm{N}\right.$ from zenith) orthogonal to the geomagnetic field lines. The details of the radar are available in the literature (Rao et al., 1995). The nighttime airglow emissions (OI $630.0 \mathrm{~nm}$ and $777.4 \mathrm{~nm}$ ) from thermosphere altitudes ( $\sim 250 \mathrm{~km}$ and $\mathrm{F}$ region peak altitude) have been monitored using a temperature controlled narrow band $(0.3 \mathrm{~nm})$ optical photometer whose field of view $\left(3^{\circ}\right)$ was chosen to nearly coincide with radar beam width. The details of this photometer (Sekar et al., 2004) and coordinated observations (Chakrabarty et al., 2005, 2006) are available in the literature. In addition to these techniques, the layer height movements of the F-region over the dip equator which correspond to zonal electric fields were obtained from the ionosonde observations located at Thumba. Due to technical reasons, the channel corresponding to $777.4 \mathrm{~nm}$ airglow emission was not operational on this night.

\section{Results}

Figure 1 depicts the combined results obtained on 26-27 April 2006 by the three independent techniques described in the previous section. The horizontal axis corresponds to time in IST (Indian standard time = Universal time, $\mathrm{UT}+5.5 \mathrm{~h}$ ) which is common to all subplots. The rangetime-intensity (RTI), range-time-velocity (RTV) and rangetime-width (RTW) maps obtained from VHF radar echoes are given in panels (a), (b) and (c). The colour codes in them correspond to strength of return echoes in Fig. 1a, line of sight Doppler velocities in Fig. 1b and spectral width in the unit of velocity in Fig. 1c. A number of isolated plumes without having bottom side structures are observed on this night. The vertical columnar intensity variations of $630.0 \mathrm{~nm}$ airglow emission corresponding to the same time interval are depicted in Fig. 1d. Corresponding to isolated plumes structures in Fig. 1a, reductions or depletions in the $630.0 \mathrm{~nm}$ 
airglow intensities are noted. Depletions in airglow intensities are observed at $\sim 23: 30, \sim 24: 00, \sim 00: 30, \sim 01: 00$ and $\sim 01: 30 \mathrm{~h}$. In addition to these, some other variations in $630.0 \mathrm{~nm}$ airglow emission are also observed before $23: 30 \mathrm{~h}$ and after 02:00 h in Fig. 1c which are not directly associated with ESF structures and will not be discussed further. The layer height variations over the dip equator (Thumba) which correspond to zonal electric field during nighttime are depicted in Fig. 1e. The importance of these isolated structures obtained $\sim 23: 30, \sim 21: 00, \sim 01: 00$ and $\sim 01: 30 \mathrm{~h}$ will be discussed in the following section.

\section{Discussion}

Though the strength of the backscattered echoes corresponding to the ESF structures till 00:30 h on 27 April 2006 were relatively intense (see Fig. 1a), they remained stationary or moved downward (see Fig. 1b). The ESF structures began to weaken after 00:30 h although the movements continued to be downward. The downward movement of these structures are evidenced both by Doppler velocities and from the location of the lower boundary of the structure compared to other structures. The variation of the base height of $F$ region in the lowest panel also verifies the slow downward motion. The spectral widths corresponding to all the five structures are $\leqslant 25 \mathrm{~m} / \mathrm{s}$. As these spectral widths are small compared to the corresponding width $(>50 \mathrm{~m} / \mathrm{s})$ for well developed ESF structure. Thus these structures were less turbulent. This supports that these structures are not in evolutionary stages.

The airglow intensity recorded depletions corresponding to all these five structures. This airglow intensity is directly proportional to electron density. Further, as these structures are isolated patches, depleted airglow intensities can be taken to be due to the presence of plasma depletion structures with respect to background. It is to be noted here that the variations in $630.0 \mathrm{~nm}$ airglow intensity not only depend on the electron density variations but also depend inversely on the layer height variation. In order to ensure the airglow intensity variations recorded corresponding to these ESF structures are essentially due to plasma depletions, the F-region layer height variations (Fig. 1e) are examined. The F-region height remained nearly stationary or was moving downward during these intervals. Downward motion of the F layer generally increases the $630.0 \mathrm{~nm}$ airglow intensity. Therefore, based on the airglow intensity variations, radar plots corresponding to these ESF structures and ionosonde observations, it can be inferred that these structures are "fossil bubbles" which were not moving upward as that of the conventional plasma bubble in developing phase.

It is important, nevertheless, to understand how such fossil bubbles can maintain $3 \mathrm{~m}$-scale irregularities and remain "active". A close scrutiny of Fig. 1 reveals that the irregularities are located mostly on the rising edge of the airglow depletions. As pointed out by Woodman and La Hoz (1976), a narrow field of view detector acts like a slit camera and for a frozen-in structure moving east, the viewpoint is that of looking south along the earth's magnetic field lines. Thus, the active region is on the western edge of the fossil bubble. Such a region has a density gradient pointing westward. This gradient is unstable to the wind driven Instability (Kelley, 1989) if the eastward wind exceeds the plasma drift, as it must for an F region dynamo. During the pre-midnight hours similar to the present case, the wind and plasma drifts approach each other and the growth rate decreases reducing the backscattered intensity corresponding to these irregularities. The spectral widths corresponding to the pre-midnight hours are expected to be less since the r.m.s. velocity is proportional to $(U-V)$, where $U$ is the eastward wind and $V$ is the eastward plasma drift whereas during post sunset hours, it is proportional to $g / v_{i n}$, where $v_{i n}$ is the ion-neutral collision frequency and $g$ is acceleration due to gravity. For higher altitudes, this velocity is much larger than $(U-V)$. Thus the neutral wind driven instability is suggested to destabilize the fossil bubbles and make them active.

\section{Summary}

An example of identifying "fossil bubbles" associated with ESF using coordinated measurements of VHF radar and airglow is obtained. Downward moving plume structures and corresponding depletions in OI $630.0 \mathrm{~nm}$ airglow intensity reveal that these structures are "fossil bubbles". The layer height variations support the conclusion that the recorded airglow intensity variations are only to plasma density depletions. Analysis of the location of the $3 \mathrm{~m}$ irregularity structures suggest strongly that these are due to neutral wind driven instability.

Acknowledgements. The authors thank the Director and the staff members of the National Atmospheric Research Laboratory for their cooperation in making the observational campaign successful. This work is supported by the Department of Space, Government of India.

Topical Editor M. Pinnock thanks one anonymous referee for her/his help in evaluating this paper.

\section{References}

Argo, P. E. and Kelley, M. C.: Digital Ionosonde Observations During Equatorial Spread F, J. Geophys. Res., 91, 5539-5555, 1986.

Basu, S., Basu, Su., Aarons, J., McClure, J. P., and Cousins, M. D.: On the coexistence of kilometer- and meter-scale irregularities in the nighttime equatorial F region. J. Geophys. Res., 83, 42194226, 1978.

Chakrabarty, D., Sekar, R., Narayanan, R., Devasia, C. V., and Pathan, B. M.: Evidence for the interplanetary electric field effect on the OI $630.0 \mathrm{~nm}$ airglow over low latitude, J. Geophys. Res., 110, A11301, doi:10.1029/2005JA011221, 2005. 
Chakrabarty, D., Sekar, R., Narayanan, R., Patra, A. K., and Devasia, C. V.: Effect of interplanetary electric field on the development of an spread F event, J. Geophys. Res., 111, A12316, doi:10.1029/2006JA011884, 2006.

Fukao, S., Yokoyama, T., Yamamoto, M., Maruyama, T., and Saito, S.: Onset of F-region plasma plumes observed with Equatorial Atmosphere Radar in Indonesia, Proceedings of XXVIII URSI General Assembly, New Delhi, 2005.

Hanumath Sastri, J.: Post-midnight onset of spread F at Kodaikanal during the June solstice of solar minimum, Ann. Geophys., 17, 1111-1115, 1999, http://www.ann-geophys.net/17/1111/1999/.

Kelley, M. C.: Equatorial spread F: recent results and outstanding problem, J. Atmos. Sol. Terr. Phys., 47, 745-752, 1985.

Kelley, M. C.: The Earths ionosphere: Plasma physics and electrodynamics, International Geophysics Series, vol. 43, Academic Press, 1989.
Ossakow, S. L.: Spread F theories: A review, J. Atmos. Terr. Phys., 43, 437-452, 1981.

Rao, P. B., Jain, A. R., Kishore, P., Balmuralidhar, P., Damle, S. H., and Vishwanathan, G.: Indian MST radar, System description and sample vector wind measurements in ST mode, Radio Sci., 30, 1125-1138, 1995.

Sekar, R., Suhasini, R., and Raghavarao, R.: Effects of vertical winds and electric fields in the nonlinear evolution of equatorial spread F, J. Geophys. Res., 99, 2205-2213, 1994.

Sekar, R., Chakrabarty, D., Narayanan, R., Sripathi, S., Patra, A. K., and Subbarao, K. S. V.: Characterization of VHF radar observations associated with equatorial Spread $\mathrm{F}$ by narrow-band optical measurements, Ann. Geophys., 22, 3129-3136, 2004, http://www.ann-geophys.net/22/3129/2004/.

Woodman, R. F. and La Hoz, C.: Radar observations of F region equatorial irregularities, J. Geophys. Res., 81, 5447-5466, 1976. 